\title{
Atypical Presentation of Pretibial Myxoedema in Graves' Disease
}

\author{
QT ISLAM $^{\mathrm{a}}$, ABI MOMEN $^{\mathrm{b}}$, AK KHONDOKAR $^{\mathrm{c}}$, HAMN AHASAN $^{\mathrm{d}}$, HTAHSEEN $^{\mathrm{e}}$
}

(J Bangladesh Coll Phys Surg 2017; 35: 46)

A 26-year-old man presented with gradual swelling of both legs for the last 5 years (Figure 1). The skin over the legs are thickened, with irregular nodular swelling. He also complained of significant weight loss in past few months, together with frequent passage of loose

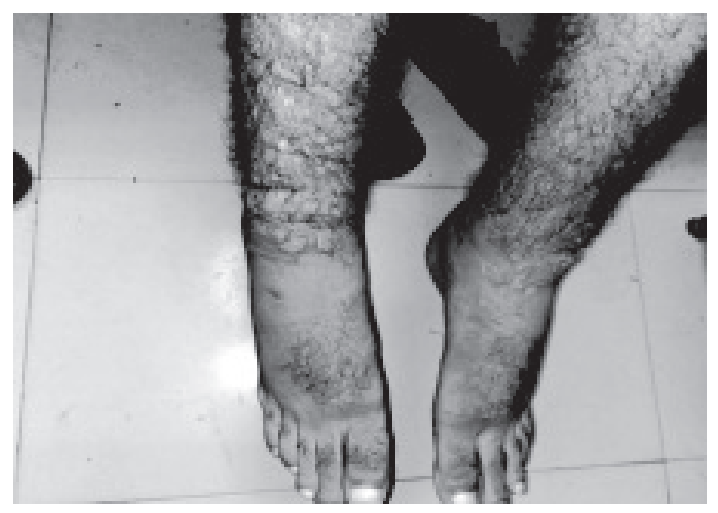

Fig .-1:

stool, sweating and palpitation. Patient was previously treated by Diethylcarbamazine as a case of Filariasis.

On examination the patient was anxious with a staring look and mildly anaemic. There was clubbing (Figure: 2) in digits of hands and feet, tachycardia, irregular nodular non tender and firm goitre with no bruit or retrosternal extension, warm and moist palm, fine tremor.

There was bilateral non pitting oedema of the legs (Figure: 3 ) and overlying skin is thick, irregular, nodular. There is no organomegaly, ascites or lymphadenopathy. There was exopthalmus, but no diplopia, opthalmoplegia, lid lag or lid retraction.
His thyroid profile revealed TSH - $0.00 \mathrm{mIU} / \mathrm{L}, \mathrm{F}-\mathrm{T} 4$ $30.27 \mathrm{pmol} / \mathrm{L}, \mathrm{F}-\mathrm{T} 3-16.51 \mathrm{pmol} / \mathrm{L}$, Anti-Thyroglobulin $\mathrm{Ab}-1.66 \mathrm{IU} / \mathrm{ml}$

The patient was diagnosed with Thyrotoxicosis due to Graves disease with Thyroid acropachy with Dermopathy. This atypical nodular dermopathy is a rare presentation in Graves diseases.

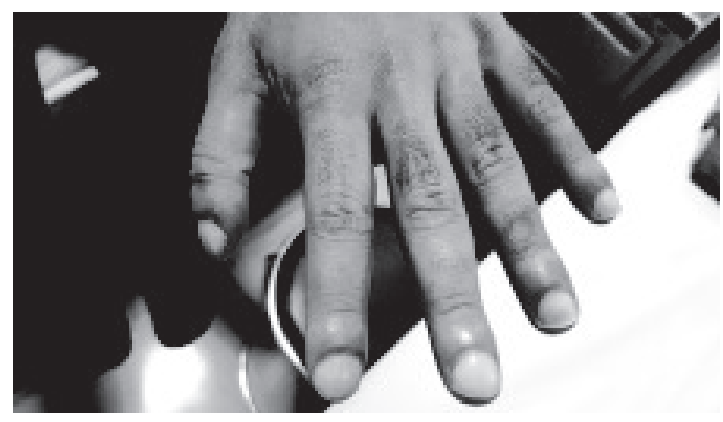

Fig .-2:

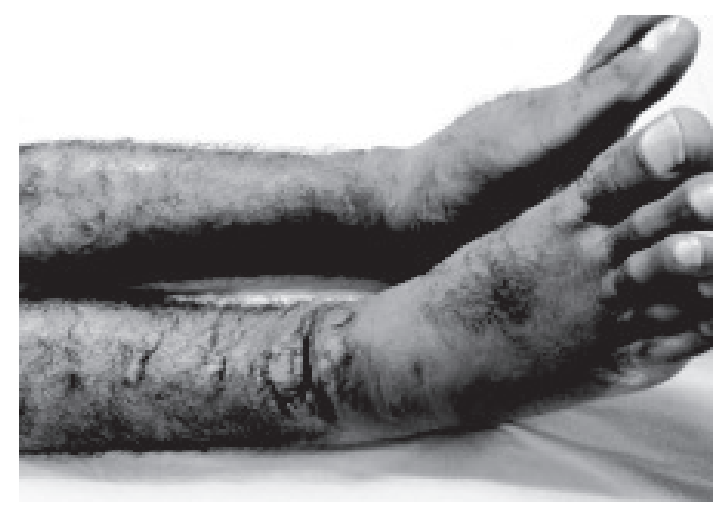

Fig .-3:

a. Quazi Tarikul Islam, Professor of Medicine, Popular Medical College, Dhanmondi, Dhaka

b. Abdul Basit Ibne Momen, Assistant Registrar of Medicine, Popular Medical College, Dhanmondi, Dhaka

c. Abul Kashem Khondokar, Professor and head of Medicine, Popular Medical College, Dhanmondi, Dhaka

d. HAM Nazmul Ahasan, Professor of Medicine, Popular Medical College, Dhanmondi, Dhaka

e. Homayra Tahseen, Associate Professor of Medicine, Popular Medical College, Dhanmondi, Dhaka

Address of Correspondence: Quazi Tarikul Islam, Professor of Medicine, Popular Medical College, Dhanmondi, Dhaka, E-mail: prof.tarik@gmail.com 